\title{
Different Training Procedures Recruit Either One or Two Critical Periods for Contextual Memory Consolidation, Each of Which Requires Protein Synthesis and PKA
}

Roussoudan Bourtchouladze, ${ }^{1,2}$ Ted Abel,${ }^{3}$ Nathaniel Berman, ${ }^{1}$ Rachael Gordon, ${ }^{1}$ Kyle Lapidus, ${ }^{1}$ and Eric R. Kandel ${ }^{1,2,4}$

${ }^{1}$ Howard Hughes Medical Institute

Center for Neurobiology and Behavior

College of Physicians and Surgeons of Columbia University

${ }^{2}$ New York State Psychiatric Institute

New York, New York 10032 USA

${ }^{3}$ Department of Biology

University of Pennsylvania

Philadelphia, Pennsylvania 19104 USA

\begin{abstract}
We have used a combined genetic and pharmacological approach to define the time course of the requirement for protein kinase A (PKA) and protein synthesis in long-term memory for contextual fear conditioning in mice. The time course of amnesia in transgenic mice that express $\mathrm{R}(\mathrm{AB})$ and have genetically reduced PKA activity in the hippocampus parallels that observed both in mice treated with inhibitors of PKA and mice treated with inhibitors of protein synthesis. This PKAand protein synthesis-dependent memory develops between $1 \mathrm{hr}$ and $3 \mathrm{hr}$ after training. By injecting the protein synthesis inhibitor anisomycin or the PKA inhibitor Rp-cAMPs at various times after training, we find that depending on the nature of training, contextual memory has either one or two brief consolidation periods requiring synthesis of new proteins, and each of these also requires PKA. Weak training shows two time periods of sensitivity to inhibitors of protein synthesis and PKA, whereas stronger training exhibits only one. These studies underscore the parallel dependence
\end{abstract}

${ }^{4}$ Corresponding author. of long-term contextual memory on protein synthesis and PKA and suggest that different training protocols may recruit a common signaling pathway in distinct ways.

\section{Introduction}

A distinguishing characteristic of long-term memory is its sensitivity to inhibitors of protein synthesis (Davis and Squire 1984). We have recently focused on the role of protein synthesis in long-term memory for contextual fear conditioning, a form of associative learning, in which animals learn to fear a new environment because of its temporal association with an aversive unconditioned stimulus (US), usually a foot shock. When exposed to the same context at a later time, conditioned animals show a variety of conditional fear responses, including freezing behavior (Fanselow 1984). In rodents, the hippocampus is essential for contextual fear (Phillips and LeDoux 1992; Kim et al. 1993; Logue et al. 1997). Because robust learning can be triggered with a single training trial, contextual fear conditioning has been used to study temporally distinct processes of short-term and long-term memory (Kim et al. 1992, 1993; Bourtchouladze et al. 1994; Kogan et al. 1996; Abel et al. 1997).

We have found that long-term memory for contextual and cued fear conditioning is sensitive to inhibitors of protein synthesis administered around

LEARNING \& MEMORY 5:365-374 @ 1998 by Cold Spring Harbor Laboratory Press ISSN1072-0502/98 \$5.00

$$
\begin{array}{lllllllllllllll}
L & E & A & R & N & I & N & G & \underset{365}{\mathbf{Z}} & M & E & M & O & R & Y
\end{array}
$$


the time of training (Abel et al. 1997). These findings suggest that long-term memory for fear conditioning requires the synthesis of new proteins, presumably as the result of the induction of new genes. Behavioral studies of mice lacking the $\alpha$ and $\delta$ isoforms of the cAMP response element-binding (CREB) protein have suggested that this transcription factor plays a crucial role in long-term memory storage (Bourtchouladze et al. 1994; Kogan et al. 1996). Moreover, CRE-mediated gene expression is induced in response to stimuli that generate longlasting forms of long-term potentiation (LTP) in the hippocampus (Impey et al. 1996).

What are the signal-transduction pathways that mediate these processes of gene induction during the consolidation of short-term memory into longterm memory? Studies of implicit memory in Aplysia and Drosopbila suggested that the cAMP/PKA pathway is a core-signaling transduction pathway for memory storage (Kandel and Schwartz 1982; Kaang et al. 1993; Li et al. 1995). To explore this issue in mammals, we generated transgenic mice that express $\mathrm{R}(\mathrm{AB})$, an inhibitory form of the regulatory subunit of PKA, in neurons within the forebrain. $\mathrm{R}(\mathrm{AB})$ transgenic mice have reduced hippocampal PKA activity and have selective impairments in hippocampus-dependent long-term memory and the late phase of LTP in area CA1. This long-term memory deficit paralleled that observed when anisomycin, an inhibitor of protein synthesis, was administered to wild-type mice at the time of training in conditioned fear tasks (Abel et al. 1997).

These studies left open the question of whether there is only one or multiple consolidation periods for this form of memory storage. If so, is the requirement for protein synthesis invariably associated with a requirement for PKA? Although most studies have emphasized the importance of a single consolidation phase sensitive to inhibitors of protein synthesis at or around the time of training (Barraco and Stettner 1976; Davis and Squire 1984), other studies have suggested that there are two or more sensitive periods during which protein synthesis inhibitors exert amnesic effects (Grecksch and Matthies 1980; Freeman et al. 1995; Chew et al. 1996). For example, two distinct time windows for the amnesic effect of the protein synthesis inhibitor anisomycin were reported for a passive avoidance task in chicks (Freeman et al. 1995). At the molecular level, multiple waves of protein and gene induction have been observed during long-term facilitation in Aplysia (Barzilai et al. 1989) and LTP in the mammalian hippocampus (Abraham et al. 1993). This has led to the idea that under certain circumstances more than one phase of protein synthesis may be necessary for long-term memory storage.

Using both genetic and a pharmacological approaches, we find that the time course of the memory deficit in contextual fear conditioning resulting from the injection of an inhibitor of protein synthesis, anisomycin, or by the injection of RpcAMPs, an inhibitor of PKA, is parallel to that observed in $\mathrm{R}(\mathrm{AB})$ transgenic mice. By injecting anisomycin (ANI) or Rp-cAMPs at various times after training, we have observed a single sensitive period after a strong training paradigm. In contrast, when a weaker training procedure is used, two sensitive periods for long-term contextual memory are revealed. These studies indicate that different training protocols may recruit these molecular processes in distinct ways, but in both cases, the requirement for protein synthesis is matched by a requirement for PKA.

\section{Materials and Methods}

\section{CONTEXTUAL FEAR CONDITIONING}

Fear conditioning experiments were done as described (Bourtchouladze et al. 1994; Abel et al. 1997). On the training day, the mouse was placed in the conditioning chamber (Med Associates) for 2 min before the onset of the conditioned stimulus (CS), a tone, which lasted for $30 \mathrm{sec}$ at $2800 \mathrm{~Hz}, 85$ $\mathrm{dB}$. The last $2 \mathrm{sec}$ of the CS was paired with the unconditioned stimulus (US), $0.7 \mathrm{~mA}$ of continuous foot shock. After an additional $30 \mathrm{sec}$ in the chamber, the mouse was returned to its home cage. In the experiments with three CS/US pairings, $0.5-\mathrm{mA}$ shocks were given with a 1 -min intertrial interval. Conditioning was assessed by scoring freezing behavior, which was defined as the complete lack of movement, in intervals of $5 \mathrm{sec}$. Contextual conditioning was assessed for 3 consecutive min in the chamber in which the mice were trained.

In experiments with $\mathrm{R}(\mathrm{AB})$ transgenic mice, controls always included wild-type littermates of the mutants. As in our previous study (Abel et al. 1997), we used an equal number of mice from the $\mathrm{R}(\mathrm{AB})-1$ and $\mathrm{R}(\mathrm{AB})-2$ transgenic lines for each testing time point. Transgenic mice were generated as described (Abel et al. 1997). In this study we used mice with three to five backcrosses into C57BL/6J




mice. We used 10- to 14-week-old male and female mice. For genotyping, tail DNA was prepared and analyzed by Southern blotting with a transgenespecific probe (Abel et al. 1997).

For ANI and Rp-cAMPs studies, we used 10- to 14-week-old C57BL/6J male mice (Jackson Labs). ANI (Sigma) was dissolved in $0.9 \%$ saline, and the $\mathrm{pH}$ was adjusted with $1 \mathrm{~N} \mathrm{HCl}$ to 7.4. Mice were subcutaneously injected with $150 \mathrm{mg}$ of ANI/kg of body weight, or an equivalent volume of saline. At this dosage, ANI inhibits cerebral protein synthesis in mice by $\sim 96 \%, 15-45 \mathrm{~min}$ after injection (Davis and Squire 1984).

For the injection of Rp-cAMPs, mice were anesthetized with $20 \mathrm{mg} / \mathrm{kg}$ Avertin and implanted with a 20-gauge guide cannula into the lateral ventricle (coordinates: $\mathrm{A}=0.5 \mathrm{~mm}, \mathrm{~L}=1 \mathrm{~mm}$ to a depth of $1.5 \mathrm{~mm}$; Franklin and Paxinos 1997). Four to seven days after recovery from surgery, animals were trained for contextual fear conditioning. RpcAMPs, an inhibitor of PKA (Wang et al. 1991) (BioLog) was dissolved in distilled water and injected $(110 \mathrm{~nm} / 3 \mu \mathrm{l})$ into the lateral ventricle. The dosage of Rp-cAMPs used was based on our pilot studies and work by Self and Nestler (1995). The infusion was made through the infusion cannula that was connected to a microsyringe by a polyethylene tube. The entire infusion procedure took $\sim 1 \mathrm{~min}$, and animals were handled gently to minimize stress. Control animals received injections of distilled water. After the end of the behavioral procedures, $3 \mu \mathrm{l}$ of a solution of $4 \%$ methylene blue was infused into the cannula. Animals were sacrificed and their brains were removed, frozen, and then cut at $-20^{\circ}$ with cryostat for histological localization of infusion cannula.

In experiment 1 , mice were injected with ANI or Rp-cAMPs immediately after training ( $0 \mathrm{~min}$ ). Mice were tested for contextual fear conditioning at $1,3,6$, or $24 \mathrm{hr}$ after training. In experiment 2 , mice were injected at $0,1,4,6,8$, or $23.5 \mathrm{hr}$ after training. Mice were evaluated for contextual fear conditioning at $24 \mathrm{hr}$ after training.

Mice were maintained and bred under standard conditions, consistent with National Institutes of Health (NIH) guidelines and approved by the Institutional Animal Care and Use Committee.

\section{DATA ANALYSIS}

Experimentally naive mice were used for the time points tested in all experiments. Experiments were designed in a balanced fashion, and mice were trained and tested at each of the different time points in three or four separate experiments. Experiments were analyzed with an analysis of variance (ANOVA) with drug or genotype as main effect [for inhibitors and $\mathrm{R}(\mathrm{AB})$ studies, respectively]. All values in the text and figure legends are expressed as mean \pm S.E.M. The experimenter was blind to the genotype or drug treatment in all studies, and the statistical analysis was performed blind.

\section{Results}

THE TIME COURSE OF AMNESIA IN ANIMALS TREATED WITH ANI OR Rp-cAMPs PARALLELS THAT OBSERVED IN R(AB) MUTANTS

In our previous study, we found that memory for contextual and cued fear conditioning is sensitive to the injection of a protein synthesis inhibitor around the time of training when animals were tested $24 \mathrm{hr}$ after training (Abel et al. 1997). To extend these findings, we have now asked: What is the time course of the protein synthesis-dependent memory for contextual fear conditioning? To address this question, we trained mice with a single CS/US pairing and injected them with ANI or vehicle immediately after training. Mice were than tested in this same context at 1, 3, 6, or $24 \mathrm{hr}$ after training (Fig. 1A). ANI-injected animals exhibited normal performance when tested at $1 \mathrm{hr}$ after training $(P<0.05)$, but retention was significantly impaired at 3, 6, and $24 \mathrm{hr}$ after training $(P<0.001$, Fig. 1A).

Next, we explored how this protein synthesisdependent memory related to the long-term contextual memory that is sensitive to the inhibition of PKA. The genetic reduction of hippocampal PKA activity in mice that express $\mathrm{R}(\mathrm{AB})$, an inhibitory form of the regulatory subunit of PKA, selectively impairs hippocampus-dependent long-term memory and the late phase of LTP in area CA1 (Abel et al. 1997). To extend these findings, we have now asked whether the time course of amnesia for contextual memory in $\mathrm{R}(\mathrm{AB})$ transgenic mice correlates with the time course of amnesia in ANI-treated mice. We trained $\mathrm{R}(\mathrm{AB})$ transgenic and wild-type mice with a single CS/US pairing and tested them at 1, 3, 6, or $24 \mathrm{hr}$ after training. As Figure $1 \mathrm{C}$ shows, $\mathrm{R}(\mathrm{AB})$ transgenic mice and controls displayed similar levels of freezing at $1 \mathrm{hr}$ after training $(P<0.05)$. In contrast, $\mathrm{R}(\mathrm{AB})$ mutant mice showed a dramatic reduction in contextual fear

$$
\begin{array}{lllllllllllllll}
L & E & A & R & N & I & N & G & \underset{367}{\boldsymbol{Z}} & M & E & M & O & R & Y
\end{array}
$$


responses relative to wild-type controls when tested 3, 6, and $24 \mathrm{hr}$ after training $(P<0.01$ and $P<0.001$, Fig. 1C). Thus, $\mathrm{R}(\mathrm{AB})$ mice have normal short-term memory but reduced long-term memory, and this memory deficit is already apparent at $3 \mathrm{hr}$ after training. Moreover, the time course of amnesia in $\mathrm{R}(\mathrm{AB})$ transgenic mice parallels that observed in ANI-treated mice.

Although the $\mathrm{R}(\mathrm{AB})$ transgenic mice exhibited very selective impairments in long-term memory, one concern about genetically modified mice is the potential for developmental effects as a result of transgene expression. To directly demonstrate an acute role for PKA in contextual fear conditioning, we turned to a pharmacological approach and used Rp-cAMPs, an inhibitor of protein kinase A (PKA; Wang et al. 1991). To evaluate the time course of Rp-cAMPs-sensitive memory for contextual fear conditioning, we injected Rp-cAMPs into the lat- eral ventricle immediately after a single CS/US pairing and tested mice in the same context at 1, 3, 6, or $24 \mathrm{hr}$ after training (Fig. 1B). Rp-cAMPs-injected mice and controls showed similar levels of freezing at $1 \mathrm{hr}$ after training $(P>0.05)$. In contrast, RpcAMPs-injected animals showed significantly less freezing than vehicle-injected mice when tested 3 , 6 , and $24 \mathrm{hr}$ after training $(P<0.01$ and $P<0.001$, Fig. 1B).

To examine whether Rp-cAMPs has an effect on the initial acquisition of fear conditioning, we injected mice 20 min before contextual fear conditioning. We found that immediate freezing responses were similar in PKA inhibitor- and vehicleinjected mice $34.2 \pm 5.5 \%$ and $38.3 \pm 5.8 \%$ for vehicle- and drug-injected animals, respectively, $P>0.05 ; n=7$ in each group). In contrast, when these mice were tested at $24 \mathrm{hr}$ after training, RpcAMPs-injected mice showed a dramatic deficit in
Figure 1: The time course of amnesia in ANI and Rp-cAMPs-treated mice parallels that observed in $\mathrm{R}(\mathrm{AB})$ transgenic mice. $(A)$ The amnesia for contextual memory in anisomycin-injected mice develops between $1 \mathrm{hr}$ and $3 \mathrm{hr}$ after training. No significant difference in freezing responses between ANI-injected (solid bars) and vehicle-injected (open bars) mice was found $1 \mathrm{hr}$ after training $[F(1,10)=0.32, P=0.46$, $n=6$ in each group]. Freezing responses of ANI-injected mice were significantly less than those of vehicle-injected mice at $3 \mathrm{hr}$ $[F(1,14)=14.2, P<0.001, n=8$ in each group $], 6 \mathrm{hr}[F(1,14)=16.7$, $P<0.001, n=8$ in each group], and $24 \mathrm{hr}$ after training [ $F(1$, $12)=18.54, P<0.001, n=7$ in each group]. $(B)$ The amnesia for contextual memory in Rp-cAMPs-injected mice develops between $1 \mathrm{hr}$ and $3 \mathrm{hr}$ after training. No significant difference in freezing responses between Rp-cAMPs-injected (solid bars) and vehicle-injected (open bars) mice was found $1 \mathrm{hr}$ after training $[F(1,14)=1.28, P=0.27$, $n=8$ in each group]. Freezing responses of Rp-cAMPs-injected mice were significantly less than those of vehicle-injected mice at $3 \mathrm{hr}$ $[F(1,19)=13.8, P=0.001, n=10$ and $n=11$ for vehicle- and druginjected mice, respectively], $6 \mathrm{hr}[F(1,12)=10.3, P<0.01, n=7$ in each group], and $24 \mathrm{hr}$ after training $[F(1,12)=17.42, P=0.001, n=7$ in each group]. $(C)$ The amnesia for contextual memory in $\mathrm{R}(\mathrm{AB})$ transgenic mice develops between $1 \mathrm{hr}$ and $3 \mathrm{hr}$ after training. No significant difference in freezing responses between $R(A B)$ transgenic (hatched bars) and control (open bars) mice was found $1 \mathrm{hr}$ after training $[F(1,10)=0.49, P=0.50, n=6$ in each group]. Freezing responses of $\mathrm{R}(\mathrm{AB})$ transgenics were significantly less than those of control mice at $3 \mathrm{hr}[F(1,31)=7.82, P<0.01, n=14$, and $n=19$ for controls and mutants, respectively], $6 \mathrm{hr}[F(1,12)=9.01, P=0.01$, $n=6$, and $n=8$ for controls and mutants, respectively], and $24 \mathrm{hr}$ after training $[F(1,12)=25.74, P<0.001, n=7$ in each group]


$$
\begin{array}{lllllllllllllll}
L & E & A & R & N & I & N & G & \underset{368}{\mathbf{Q}} & M & E & M & O & R & Y
\end{array}
$$


freezing responses when compared to vehicle-injected mice $(43.8 \pm 5.4 \%$ and $17 \pm 5 \%$ for vehicleand drug-injected animals, respectively, $P<0.01)$.

\section{A STRONG TRAINING PROTOCOL REVEALS A SINGLE SENSITIVE PERIOD FOR THE AMNESIC ACTION OF ANI AND Rp-cAMPs}

In early studies, several researchers showed that retention is not affected if protein synthesis inhibition is initiated at progressively longer intervals after training (Geller et al. 1969; Neale et al. 1973; Davis and Squire 1984). In addition, some studies have indicated that protein synthesis inhibitors were ineffective when tasks were very well learned in the initial training sessions (Barondes and Cohen 1966; Pots and Bitterman 1967; Mayor 1969; Golub et al. 1972). This has raised two questions: (1) Does amnesic action of anisomycin depend on the extent of training? (2) What are the necessary temporal relationships between protein synthesis inhibitor treatment and training to produce amnesia?



B

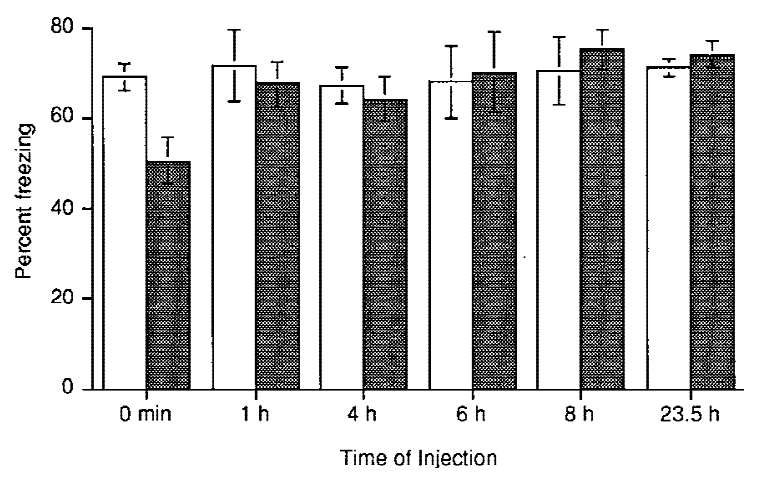

To test this, we adapted a stronger training regimen in our next set of experiments by using three pairings of the CS with the US with a 1-min intertrial interval. We injected mice with ANI at various times between training and testing, and retention was tested at $24 \mathrm{hr}$ after training. As Figure $2 \mathrm{~A}$ shows, ANI was effective when given immediately after training: Inhibitor-injected animals showed significantly less freezing than vehicle-injected mice $(P<0.001)$. However, ANI was not effective when the interval between training and treatment was increased by $1,4,6,8$, or $23.5 \mathrm{hr}$ (Fig. 2A). These data indicate that ANI is effective when the stronger training procedure is used and suggests that only a single wave of protein synthesis during or shortly after a stronger training procedure is required for long-term memory for contextual conditioning over $24 \mathrm{hr}$.

Next, we asked about the temporal relationship between PKA inhibitor treatment and training necessary to produce amnesia. We trained mice with three CS/US pairings and injected Rp-cAMPs at various times after training. Retention was tested at $24 \mathrm{hr}$ after training. Rp-cAMPs was effective
Figure 2: Sensitive periods for protein synthesis and PKA inhibitors following training with $3 \mathrm{CS} / \mathrm{US}$ pairings. $(A)$ There is one sensitive time period for the effect of ANI on contextual memory tested at $24 \mathrm{hr}$. Freezing responses of ANI-injected mice (solid bars) were significantly less than those of vehicleinjected (open bars) animals when ANI was administered at 0 hr $[F(1,19)=14.57, P<0.001, n=10$, and $n=11$ for vehicleand $\mathrm{ANI}$-injected animals, respectively]. However, no significant differences in freezing responses between ANI- and vehicle-injected mice were found when injections were made 1 hr $[F(1,14)=0.02, P=0.86, n=8$ in each group], $4 \mathrm{hr}$ $[F(1,16)=0.42, \quad P=0.68, \quad n=9$ in each group $], 6 \mathrm{hr}$ $[F(1,14)=0.24, P=0.82, \quad n=8$ in each group $], 8 \mathrm{hr}$ $[F(1,14)=0.56, P=0.59, n=8$ in each group], and $23.5 \mathrm{hr}$ after training $[F(1,14)=0.46, P=0.64, n=8$ in each group]. $(B)$ There is one sensitive time period for the effect of RpcAMPs on contextual memory tested at $24 \mathrm{hr}$. Freezing responses of Rp-cAMPs-injected mice (shaded bars) were significantly less than those of vehicle-injected animals (open bars) when Rp-cAMPs was administered at $0 \mathrm{hr}[F(1,14)=8.2$, $P=0.01, n=8$ in each group]. However, no significant differences in freezing responses between Rp-cAMPs- and vehicleinjected mice were found when injections were made $1 \mathrm{hr}$ $[F(1,10)=0.19, P=0.67, n=6$ in each group $], 4 \mathrm{hr}$ after training $[F(1,13)=0.02, P=0.87, n=7$, and $n=8$ for vehicle and Rp-cAMPs-injected animals, respectively], $6 \mathrm{hr}[F(1,10)=$ $0.05, P=0.83, n=6$ in each group $], 8 \mathrm{hr}[F(1,10)=0.31$, $P=0.59, n=6$ in each group], or $23.5 \mathrm{hr}$ after training $[F(1,10)=1.71, P=0.22, n=6$ in each group $]$. 
when injections were made immediately after training: Inhibitor-injected animals showed significantly less freezing than vehicle-injected mice ( $P<0.05$; Fig. 2B). However, Rp-cAMPs was not effective when given at $1,4,6,8$, or $23.5 \mathrm{hr}$ after training $(P<0.05$; Fig. $2 \mathrm{~B})$. It should be noted that when mice were trained with three CS/US pairings, Rp-cAMPs-treated animals showed significantly more freezing responses at $24 \mathrm{hr}$ after training than ANI-treated mice (50.5 $\pm 5 \%$ and $14 \pm 5 \%$, respectively, $P<0.001$ ), suggesting that the PKAindependent component(s) are recruited for longterm memory when mice are trained with a stronger training procedure.

To test the role of PKA further in long-term contextual memory and explore its relationship to the nature of the training procedure, we trained $\mathrm{R}(\mathrm{AB})$ transgenic mice and wild-type control animals with three CS/US pairings and tested the mice $24 \mathrm{hr}$ later. Although stronger training triggered significantly more contextual freezing in $\mathrm{R}(\mathrm{AB})$ transgenic mice $(41.5 \pm 6 \%)$ than training with a single CS/US pairing $(13 \pm 4 \%, P<0.001)$, the $\mathrm{R}(\mathrm{AB})$ transgenics still showed a contextual memory deficit when compared with wild-type mice $(63.4 \pm 4.5 \%$ and $41.5 \pm 6 \%$ for wild-type and mutants, $n=9$ and $n=14$, respectively, $P<0.05)$. It should be noted that $\mathrm{R}(\mathrm{AB})$ transgenic mice and Rp-cAMPs-treated mice showed similar freezing responses when trained with three CS/US pairings ( $41.5 \pm 6 \%$ and $50.5 \pm 5 \%$, respectively, $P<0.05$ ).

\section{A WEAK TRAINING PROTOCOL REVEALS TWO SENSITIVE PERIODS FOR THE AMNESIC ACTION OF ANI AND Rp-cAMPS}

Recent studies suggested that under certain conditions there are two or more sensitive periods during which protein synthesis inhibitors exert amnesic effects (Grecksch and Matthies 1980; Freeman et al. 1995; Chew et al. 1996). This has raised the question: Do sensitive time periods for the amnesic action of anisomycin depend on the extent of training? To test this possibility, we trained mice with a weaker training protocol, a single CS/US pairing, and tested them $24 \mathrm{hr}$ later. ANI was injected at various times between training and testing (Fig. 3A; note that data for 0-hr injection and test at $24 \mathrm{hr}$ are also shown on Fig. 1A). ANI-injected mice showed a dramatic deficit in freezing responses when the inhibitor was given immediately after training $(P<0.001)$. In addition, ANI was effective when given $4 \mathrm{hr}$ post-training
$(P<0.01)$ but not when injections were made at 1 , 6,8 , or $23.5 \mathrm{hr}$ after training (Fig. 3A), indicating that if mice are trained with a single training trial there is a second sensitive period during which protein synthesis is required.

Given that the presence of one or two periods of sensitivity to protein synthesis inhibition depends on the extent of training, we trained mice with one CS/US pairing and injected Rp-cAMPs at various times between training and testing. As Figure $3 \mathrm{~B}$ shows, there are two sensitive time periods for the Rp-cAMPs effect on contextual memory tested at $24 \mathrm{hr}$ : (1) immediately after training $(P<0.001$; note that data for 0 -hr injection and test at $24 \mathrm{hr}$ are also shown on Fig. 1B), and (2) $4 \mathrm{hr}$ after training $(P<0.01)$. We did not find changes in freezing responses when Rp-cAMPs was administered $1,6,8$, or $23.5 \mathrm{hr}$ after training, suggesting that only two time periods for PKA activation might be required for contextual long-term memory to be formed. Importantly, the sensitive periods for PKA and protein synthesis inhibitors are similar, suggesting that PKA may play a central role in the induction of new gene expression and protein synthesis.

\section{Discussion}

Several recent studies have demonstrated the importance of protein synthesis for long-lasting form of hippocampal LTP, a cellular model of memory storage in mammals. Whereas the early, transient phase of LTP is resistant to inhibitors of protein synthesis, the late phase of hippocampal LTP requires protein and RNA synthesis, as well as PKA activity (Krug et al. 1984; Frey et al. 1993; Huang and Kandel 1994; Nguyen et al. 1994). On the basis of pharmacological studies of LTP, we have begun to use genetically modified mice to investigate the relationships between the different phases of LTP and the different phases of fear conditioning (Abel et al. 1997).

Contextual fear conditioning lends itself readily to analysis of temporal phases of memory storage and to comparison with the phases of LTP. Like LTP in the Schaffer collateral pathway, fear conditioning depends on NMDA-receptor activation and has distinct protein synthesis-dependent and -independent phases (Kim et al. 1992; Huang and Kandel 1994; Abel et al. 1997). Our recent studies of transgenic mice that express $\mathrm{R}(\mathrm{AB})$, an inhibitory form of the regulatory subunit of PKA, first suggested that the requirement for protein

$$
\begin{array}{llllllllllllllll}
\hline & E & A & R & N & I & N & G & \boldsymbol{Q} \\
\mathbf{3 7 0} & M & E & M & O & R & Y
\end{array}
$$


A

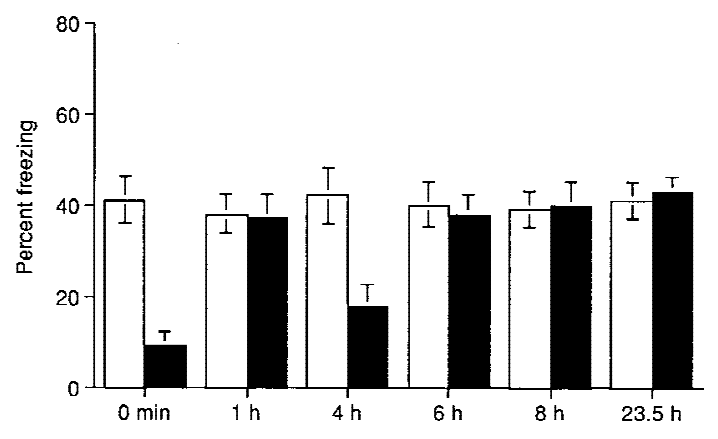

B



Figure 3: Sensitive periods for protein synthesis and PKA inhibitors following training with a single CS/US pairing. (A) There are two sensitive time periods for the effect of ANI on contextual memory tested at $24 \mathrm{hr}$. Freezing responses of ANI-injected mice (solid bars) were significantly less than those of vehicle-injected animals (open bars) when ANI was administered at $0 \mathrm{hr}[F(1$, $12)=18.54, P<0.001, n=7$ in each group; note that data for 0 -hr injection and test at $24 \mathrm{hr}$ are also shown in Fig. $1 \mathrm{~A}$ ], or $4 \mathrm{hr}$ after training $[F(1,22)=8.98, P<0.01, n=11$, and $n=13$ for vehicle- and ANI-injected animals, respectively]. No significant differences in freezing responses between ANI- and vehicle-injected mice were found when injections were made $1 \mathrm{hr}$ $[F(1,14)=0.01, \quad P=0.90, \quad n=8$ in each group $], \quad 6 \mathrm{hr}$ $[F(1,14)=0.01, \quad P=0.91, \quad n=8$ in each group $], 8 \mathrm{hr}$ $[F(1,14)=0.02, P=0.88, n=8$ in each group $]$, or $23.5 \mathrm{hr}$ after training $[F(1,10)=0.10, P=0.78, n=6$ in each group $]$. $(B)$ There are two sensitive time periods for the effect of Rp-cAMPs on contextual memory tested at $24 \mathrm{hr}$. Freezing responses of Rp-cAMPsinjected mice (shaded bars) were significantly less than those of vehicle-injected animals (open bars) when Rp-cAMPs was administered at $0 \mathrm{hr}[F(1,12)=17.42, P<0.001, n=7$ in each group; note that data for $0-\mathrm{hr}$ injection and test at $24 \mathrm{hr}$ are also shown in Fig. 1B], or $4 \mathrm{hr}$ after training $[F(1,22)=7.51, P<0.01, n=11$, and $n=13$ for vehicle- and Rp-cAMPs-injected animals, respectively]. No significant difference in freezing responses between Rp-cAMPs- and vehicle-injected mice was found when injections were made $1 \mathrm{hr}[F(1,17)=0.11, P=0.74, n=10$, and $n=9$ for vehicle- and Rp-cAMPs-injected animals, respectively], $6 \mathrm{hr}$ $[F(1,12)=0.04, P=0.84, n=7$ in each group $], 8 \mathrm{hr}[F(1,10)=0.21, P=0.66, n=6$ in each group $]$, and $23.5 \mathrm{hr}$ after training $[F(1,10)=0.06, P=0.82, n=6$ in each group]. (Open bars) Vehicle; (stippled bars) Ro-cAMPS.

synthesis of both late phase of LTP and long-term memory in contextual fear conditioning is paralleled by a requirement for PKA (Abel et al. 1997).

To define precisely the requirement of PKAand protein synthesis-dependent memory for contextual fear conditioning, we have now combined genetic and pharmacological approaches in an attempt to dissociate two temporally distinct associative contextual fear processes: a short-term PKAand protein synthesis-independent memory, and a long-term PKA- and protein synthesis-dependent memory.

We find that in mice treated with protein synthesis inhibitor, the amnesia develops between 1 and $3 \mathrm{hr}$ after training. A similar amnesia develops with inhibitor of PKA. Both of these inhibitors can be shown to interfere specifically with memory consolidation but not with retrieval, because RpcAMPs and ANI had no effect when given just before testing. In addition, we found that immediate freezing responses were similar in inhibitor- and vehicle-injected mice. In contrast, when mice were injected 20-30 min before contextual conditioning and tested at $24 \mathrm{hr}$ after training, both ANI- and
PKA inhibitor-treated mice showed dramatic amnesia when compared with vehicle-injected mice. However, we found that the injection of ANI or Rp-cAMPs $3 \mathrm{hr}$ before training ( $n=16$ total; data not shown) does not affect retention at $24 \mathrm{hr}$ after training. Taken together, these data support the idea that Rp-cAMPs and ANI do not interfere with the initial acquisition of contextual fear conditoning and that inhibitors produce amnesia when injected around the time of training.

The time course of the contextual memory deficit in inhibitor-treated mice parallels that of $\mathrm{R}(\mathrm{AB})$ transgenic mice. This supports and extends our recent findings that cAMP/PKA serves as a core signaling pathway for the consolidation of long-term hippocampus-based memory (Abel et al. 1997). These data also support the idea that the memory deficits observed in $\mathrm{R}(\mathrm{AB})$ transgenic mice are not the result of developmental defects. In addition, our data suggest that ANI and RpcAMPs affect consolidation of contextual conditioning through some common mechanisms. However, there is an alternative explanation. In the previous study (Abel et al. 1997), ANI-treated mice

$$
\begin{array}{lllllllllllllll}
L & E & A & R & N & I & N & G & \underset{371}{\mathbf{Z}} & M & E & M & O & R & Y
\end{array}
$$


were also impaired in cued conditioning, whereas $\mathrm{R}(\mathrm{AB})$ transgenic mice were not. This raises the possibility that ANI and Rp-cAMPs affect contextual memory through different mechanisms. One mechanism is PKA dependent. This PKA-dependent mechanism is important for complex cue-mediated conditioning that results in impaired contextual memory but not impaired cued memory. The other mechanism is protein synthesis dependent, which impairs even simple single cue-mediated conditioning and thus leads to impaired cued and contextual conditioning. This is supported by the fact that ANI had similar effects on contextual and cued memory (Abel et al. 1997).

PROTEIN SYNTHESIS AND PKA INHIBITORS REVEAL EITHER ONE OR TWO SENSITIVE PERIODS DEPENDING ON THE TRAINING PROTOCOL

By administering ANI and Rp-cAMPs at various times after training, we find that contextual memory has either one or two brief consolidation periods requiring both PKA and the synthesis of new proteins, depending on the nature of training. Recently, several studies have suggested that there can be two or more sensitive periods during which protein synthesis inhibitors exert amnesic effects (Grecksch and Matthies 1980; Freeman et al. 1995; Chew et al. 1996). Temporally distinct waves of protein synthesis also were found after long-term facilitation in Aplysia: a small decrease at $0.5 \mathrm{hr}$, a small increase at $1 \mathrm{hr}$, and a larger increase around $3 \mathrm{hr}$. Moreover, 5-HT also produced three temporally distinct changes in the synthesis of individual proteins (Barzilai et al. 1989). Two periods of increased PKA activity and phospho-CREB levels were recently reported for the inhibitory avoidance task in rat (Bernabeu et al. 1997).

To explore this possibility of single as opposed to multiple sensitive periods, we first examined the consequence of a strong training procedure. When mice are trained with a strong training procedure, only a single consolidation period or single time window for protein synthesis-dependent memory was found. Moreover, in this time window $\mathrm{Rp}$ cAMPs has less of an amnesic effect than ANI, and Rp-cAMPs-treated animals show significantly more freezing responses then ANI-treated mice. Similarly, $\mathrm{R}(\mathrm{AB})$ transgenic mice that were trained with the stronger procedure exhibit significantly more retention than ANI-treated mice or $\mathrm{R}(\mathrm{AB})$ transgenic mice that underwent a weaker training paradigm. However, R(AB) transgenic mice still show a memory deficit when compared with wild-type mice, indicating that stronger training compensates only partially for the long-term memory deficit of these transgenic mice. These findings suggest that when mice are trained with a strong training procedure a component of long-term memory is recruited that is independent of PKA.

Next, we examined a weak training procedure. We found that when mice are trained with a weak training procedure, ANI is effective at two distinct times: (1) when given immediately after training, and (2) when given $4 \mathrm{hr}$ after training. This suggests that two protein synthesis-sensitive time periods are required for contextual long-term memory. Therefore, we examined the requirement for PKA during each of these periods and found that in each case the period of ANI sensitivity was closely paralleled by a window, observed in mice treated with the PKA inhibitor, Rp-cAMPs. Thus, our data raise two interesting possibilities: (1) that tasks learned under different training intensities may go into long-term storage at different rates mediated by either one or two consolidation periods, and (2) independent of whether one or two periods of protein synthesis is recruited, each period of new protein synthesis-dependent memory is paralleled by a requirement for PKA. This surprising finding strengthens further the correlation between PKA and protein synthesis and raises the question: How is PKA activated for the second consolidation period after weaker training?

\section{A MOLECULAR MODEL FOR A DOUBLE CONSOLIDATION PHASE}

Weak training shows two time periods of sensitivity for PKA and protein synthesis inhibitors, whereas stronger training shows only one. This suggests that stronger training recruits a variety of signal transduction pathways immediately after training, presumably allowing sufficient genes to be turned on at the outset of training and leading to only one consolidation period. Support for this recruitment of additional pathways by stronger training comes from our data showing that the inhibition of PKA has less of an effect on memory after stronger training. Weaker training, in contrast, requires a second consolidation period during which memory storage is sensitive to inhibitors of protein synthesis and PKA.

What are the mechanisms whereby PKA is recruited for a second time? In long-term facilitation in Aplysia, the initial recruitment of PKA activates

$$
\begin{array}{lllllllllllllll}
L & E & A & R & N & I & N & G & \begin{array}{l}
\boldsymbol{Q} \\
\mathbf{3 7 2}
\end{array} & M & E & M & O & R & Y
\end{array}
$$


CREB, which leads to the induction of a set of CREB-activated immediate response genes. One of these, carboxy-terminal ubiquitin hydrolase, is neuron specific. This hydrolase is a rate-limiting step in ubiquitin-mediated proteolysis, which leads to cleavage of the regulatory subunit of PKA (Hegde et al. 1997). This cleavage leads to the establishment of a persistently active kinase that carries the facilitation for the first $10-12 \mathrm{hr}$ at which point structural changes are thought to take over. A similar mechanism may also be operating in the hippocampus to ensure that PKA can serve repeatedly as a signaling pathway to the nucleus. Interestingly, the second time period of sensitivity for PKA and protein synthesis inhibitors observed in our study coincides with the increase in cAMP levels and phospho-CREB immunoreactivity in the hippocampus observed after an inhibitory avoidance paradigm (Bernabeu et al. 1997). Inhibitory avoidance training in rats also results in a learning-specific, time-dependent increase binding to D1/D5 receptors in the hippocampus. This learning-induced change occurred between 3 and $6 \mathrm{hr}$ post-training, the same critical period when D1/D5 agonists and antagonists modulate memory consolidation. This suggests the interesting possibility that weak training in our experiments recruit a dopaminergic modulatory pathway that activates PKA with a slower time course, thus leading to a second PKAsensitive period of protein synthesis-dependent long-term memory.

\section{Acknowledgments}

We thank Thomas Deuel for help with genotyping the mice, Mohamed Osman and members of his staff for assistance with animal care, Harriet Ayers and Millie Pellan for typing the manuscript, and Chuck Lam for help in preparing the figures. This work was supported by the National Institutes of Health, NARSAD, and the Howard Hughes Medical Institute.

The publication costs of this article were defrayed in part by payment of page charges. This article must therefore be hereby marked "advertisement" in accordance with 18 USC section 1734 solely to indicate this fact.

\section{References}

Abel, T., P. Nguyen, M. Barad, T. Deuel, E.R. Kandel, and R. Bourtchouladze. 1997. Genetic demonstration of a role for PKA in the late phase of LTP in the hippocampus-based long-term memory. Cell 88: 615-626.

Abraham, W.C., S.E. Mason, J. Demmer, J.M. Williams, C. Richardson, W. Tate, P.A. Lawlor, and M. Dragunow. 1993. Correlation between immediate early gene induction and the persistence of long-term potentiation. Neuroscience 56: 717-727.
Barondes, S.H. and H.D. Cohen. 1966. Puromycin effect on successive phases of memory storage. Science 151: 594-595.

Barracco R.A. and L.J. Stettner. 1976. Antibiotics and memory. Psychol. Bull. 83: 242-302.

Barzilai A., T.E. Kennnedy, J.D. Sweat, and E.R. Kandel. 1989. 5-HT modulates protein synthesis and the expression of specific proteins during long-term facilitation in Aplysia sensory neurons. Neuron 2: 1577-1586.

Bernabeu, R., L. Bevilaqua, P. Ardenghi., E. Bromberg, P. Schmitz, M. Bianchin, I. Izquierdo, and J. Medina. 1997. Involvement of hippocampal cAMP/cAMP-dependent protein kinase signaling pathways in a late memory consolidation phase of aversively motivated learning in rats. Proc. Natl. Acad. Sci. 94: 7041-7046.

Bourtchouladze, R., B. Frenguelli, J. Blendy, D. Cioffi, G. Schutz, and A.J. Silva. 1994. Deficient long-term memory in mice with targeted mutation of the cAMP-responsive element-binding protein. Cell 79: 59-68.

Chew, S., D. Vicario, and F. Nottebohm. 1996. Quantal duration of auditory memories. Science 274: 1909-1914.

Davis, H.P. and L.R. Squire. 1984. Protein synthesis and memory: A review. Psychol. Bull. 96: 518-559.

Fanselow, M.S. 1984. What is conditioned fear? Trends Neurosci. 7: 460-462.

Franklin, K.B. and G. Paxinos. 1997. The mouse brain in stereotaxic coordinates. Academic Press, San Diego, CA.

Freeman, F., S.P. Rose, and A. Scholey. 1995. Two time windows of anisomycin- induced amnesia for passive avoidance training in the day-old chick. Neurobiol. Learn. Mem. 63: 291-295.

Frey, U., Y.-Y. Huang, and E.R. Kandel. 1993. Effects of cAMP simulate a late stage of LTP in hippocampal CA1 neurons. Science 260: 1661-1664.

Geller, A., F. Robustelli, S.H. Barondes, H.D. Cohen, and M. Jarvick. 1969. Impaired performance by post-trial injections of cycloheximide in a passive avoidance task. Psychopharmacologia 14: 371-376.

Golub, M.S., M.L. Cheal, and R.E. Davis. 1972. Effects of electroconvulsive shock and puromycin on operant responding in goldfish. Physiol. Behav. 8: 573-578.

Grecksch G. and H. Matthies. 1980. Two sensitive periods for the amnesic effect of anisomycin. Pharmacol. Biochem.Behav. 12: 663-665.

Hegde, A.N., K. Inokuchi, W. Pei, A. Casadio, M. Ghirardi, D.G. Chain, K.C. Martin, E.R. Kandel, and J.H. Schwartz. 1997. Ubiquitin C-terminal hydrolase is an immediate-early gene essential for long-term facilitation in Aplysia. Cell 89: $115-126$.

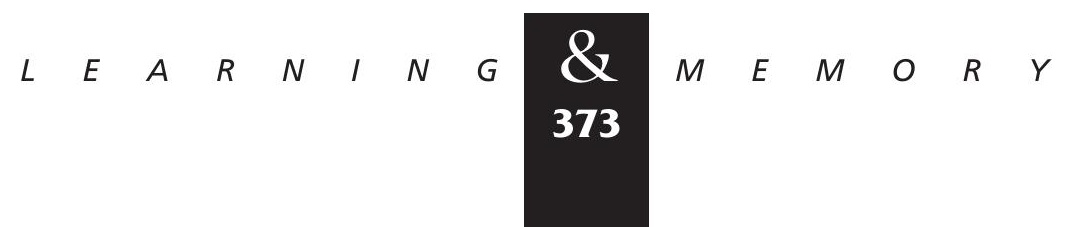




\section{Bourtchouladze et al.}

Huang, Y.-Y. and E.R. Kandel. 1994. Recruitment of long-lasting and protein kinase A-dependent long-term potentiation in the CA1 region of hippocampus requires repeated tetanization. Learn. \& Mem. 1: 74-82.

Impey, S., M. Mark, E.S. Villacres, S. Poser, C. Chavkin, and D.R. Storm. 1996. Induction of CRE-mediated gene expression by stimuli that generate long-lasting LTP in area CA1 of the hippocampus. Neuron 16: 973-982.

Kaang, B.-K., E.R. Kandel, and S. Grant. 1994. Activation of cAMP-responsive genes by stimuli that produce long-term facilitation in Aplysia sensory neurons. Neuron 10: 427-435.

Kandel, E.R. and J.H. Schwartz. 1982. Molecular biology of learning: Modulation of transmitter release. Science

218: 433-443.

Kim, J.J, M.S. Fanselow, J. DeCola, and J.

Landeira-Fernandez. 1992. Selective impairment of long-term but not short-term conditional fear by the $\mathrm{N}$-methyl-D-aspartate antagonist APV. Behav. Neurosci. 106: $591-596$.

Kim, J.J., R. Rison, and M.S. Fanselow. 1993. Effects of amygdala, hippocampus and periaqueductal gray lesions on short- and long-term contextual fear. Behav. Neurosci. 107: 1093-1098.

Kogan, J.H, P.W. Frankland, J. Blendy, J. Coblentz, Z. Marowitz, G. Schutz, and A.J. Silva. 1996. Spaced training induces normal long-term memory in CREB mutant mice. Curr. Biol. 7: 1-11.

Krug, M., B. Loessner, and T. Ott. 1984. Anisomycin blocks late phase of long-term potentiation in dentate gyrus in freely moving rats. Brain Res. Bull. 13: 39-42.

Li, W., T. Tully, and D. Kalderon. 1995. Effects of a conditional Drosophila PKA mutant on olfactory learning and memory. Learn. \& Mem. 2: 320-333.

Logue, S.F., R. Paylor, and J.M. Wehner. 1997. Hippocampal lesions cause learning deficits in inbred mice in the Morris water maze and conditioned fear task. Behav. Neurosci. 111: 104-113.

Mayor, S.J. 1969. Memory in the Japanese quail. Effects of puromycin and acetoxycloheximide. Science

166: $1165-1167$.

Neale, J., P. Klinger, and B. Agranoff. 1973.

Temperature-dependent consolidation of puromycin-

susceptible memory in goldfish. Behav. Biol. 9: 267-278.

Nguyen, P.V., T. Abel, and E.R. Kandel. 1994. Requirement of a critical period of transcription for induction of a late phase of LTP. Science 265: 1104-1107.

Phillips, R. and J.E. LeDoux. 1992. Differential contribution of amygdala and hippocampus to cued and contextual fear conditioning. Behav. Neurosci. 106: 274-285.
Potts, A. and M.F Bitterman. 1967. Puromycin and retention in the goldfish. Science 158: 1594-1596.

Self, D.W. and E.S. Nestler. 1995. Molecular mechanisms of drug reinforcement and addiction. Annu. Rev. Neurosci. 18: $463-495$.

Wang, L.-Y., M.W. Salter, and J.F. McDonald. 1991. Regulation of kinase receptors by cAMP-dependent protein kinase phosphatases. Science 253: 1132-1135.

Received April 17, 1998; accepted in revised form July 17, 1998.

$$
\begin{array}{lllllllllllllllll}
\hline & E & A & R & N & I & N & G & \mathbf{Q} & M & E & M & O & R & Y
\end{array}
$$




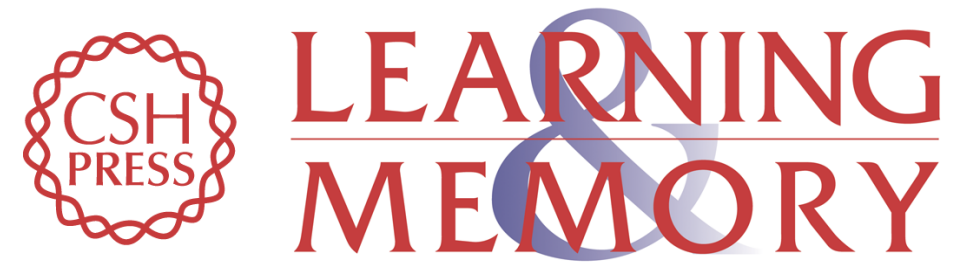

\section{Different Training Procedures Recruit Either One or Two Critical Periods for Contextual Memory Consolidation, Each of Which Requires Protein Synthesis and PKA}

Roussoudan Bourtchouladze, Ted Abel, Nathaniel Berman, et al.

Learn. Mem. 1998, 5:

Access the most recent version at doi:10.1101//m.5.4.365

References This article cites 31 articles, 11 of which can be accessed free at: http://learnmem.cshlp.org/content/5/4/365.full.html\#ref-list-1

License

Email Alerting

Receive free email alerts when new articles cite this article - sign up in the box at the Service top right corner of the article or click here. 